\section{Anticipatory responses in a linear maze*}

\author{
R. ALLEN GARDNER and WILLIAM R. GAMBONI $\dagger$ \\ Universityof Nevada, Reno, Nev. 89507
}

The findings of Sprow (1947) and Gladstone (1948) for a four-unit linear maze with homogeneous choices (LLLL or RRRR) and those of Carpenter (1952) with all choices homogeneous except for the last unit (LLLR or RRRL) were replicated within a single experiment.

When rat $\mathrm{Ss}$ are trained in a linear maze of the type illustrated in Fig. 1, the sequence of left and right correct choices is a major determinant of performance. Let us number the units in sequence from 1 to 4 , beginning with the first choice point after the startbox. Sprow (1947) and Gladstone (1948) found that, if the sequence of correct choices was homogeneous (LLLL or RRRR), then the largest number of errors was made at Unit 1 , and there was a nearly monotonic decreasing gradient of errors from Unit 1 to Unit 4. Carpenter (1952) found that, if the sequence of correct choices was homogeneous except for the last choice (LLLR or RRRL), then the largest number of errors was made at Unit 3 and the gradient of errors decreased backwards to Unit 1 .

The results found by Sprow and Gladstone were to be expected from the goal-gradient principle, as are Carpenter's results, if errors at the first three choice points are described as anticipatory errors when the sequence of correct choices is LLLR or RRRL. These results have been quoted widely in standard sources (e.g., Kimble, 1961); they were precisely what would be predicted from almost any existing theory of instrumental conditioning. Perhaps, because of this lack of controversy or because of unpopularity of the linear maze, no further replications have been reported. Yet if anticipatory errors in the linear maze are, indeed, so sensitive to the effects of the goal gradient, then the technique is a potentially valuable one for the solution of more current issues. In particular, we planned to use it to study the differential effects of partial and continuous terminal reward on the sequence of responses in a chain. Before doing so, it was necessary to demonstrate that the original results could be replicated in our laboratory.

* This experiment was supported by research funds of the Graduate School of the University of Nevada. Reno, and by a NASA predoctoral fellowship awarded to W. R. Gamboni. Requests for reprints should be mailed to R. Allen Gardner, Department of Psychology, University of Nevada, Reno. Nev. 89507.

$+N o w$ at Chicago State College.
We conducted this replication as a formal experiment so that the results could be generally available. APPARATUS

The basic plan of the test apparatus is shown in Fig. 1. It consisted of a startbox (S), four identical choice units, and a goalbox (G). The walls were $30.5 \mathrm{~cm}$ (12 in.) high and were

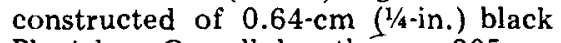
Plexiglas. Overall length was $305 \mathrm{~cm}$ $(10 \mathrm{ft})$. The start- and goalboxes were $15.2 \times 30.5 \mathrm{~cm}(6 \times 12 \mathrm{in}$.$) and$ $30.5 \times 30.5 \mathrm{~cm}$ ( $12 \times 12$ in.), respectively, and were separated from the choice units by $0.32-\mathrm{cm}$ (1/8-in.) Plexiglas guillotine doors. A $6.37-\mathrm{cm}$ (21/2-in.) square door of clear Plexiglas was located at the center and flush with the floor of the rear wall of the goalbox to allow access to a water cup (R). Each choice unit was $61 \mathrm{~cm}$ (24 in.) long and contained two $0.32 \times 10.2 \times 10.2 \mathrm{~cm}(1 / 8 \times 4 \times 4$ in.) Plexiglas doors (D) that were painted flat white. These doors were hinged at the top so that $S$ could open them by pushing forward. Retracing was not possible because the doors opened only in one direction. A stopping bolt could be placed above and behind one of the doors in each unit in such a way that it was not visible to $S$. These stopping bolts not only prevented $S$ from proceeding through the door designated as incorrect, but also permitted the automatic recording of errors by means of magnetic switches.

The entire apparatus rested on a hardwood floor painted glossy black. The floor of each unit was covered with $38.1-\mathrm{cm}$-wide (15 in.), $30 \mathrm{lb}$ brown Kraft paper that extended from $25.4 \mathrm{~cm} \mathrm{(10} \mathrm{in.)} \mathrm{before} \mathrm{to} 12.7 \mathrm{~cm}$
2 FEET
( 5 in.) behind the door. This paper flooring was pulled from rolls at the side of each unit after every trial in order to provide new paper flooring for each run.

The pretraining apparatus consisted of a $10.2-\mathrm{cm}$-wide (4 in.) alley, $142 \mathrm{~cm}$ (56 in.) in length with $30.5-\mathrm{cm}-$ high (12 in.) walls. Four panel doors were spaced in equal intervals along this alley. The same start- and goalboxes used with the test apparatus were also used with the pretraining apparatus. The alley floor at each door location was covered with a permanent sheet of 30-lb brown Kraft paper that extended from $10.2 \mathrm{~cm}$ (4 in.) before to $10.2 \mathrm{~cm}$ ( 4 in.) behind the door.

\section{PROCEDURE}

For 9 days prior to pretraining, all Ss were handled $2 \mathrm{~min}$ daily and adapted to a $23^{1 / 2}-\mathrm{h}$ water-deprivation schedule. During this time and throughout the experiment, Purina Laboratory Chow was always available in the individual living cages.

Pretraining involved three stages necessary to train the Ss to: (1) take water from the water cup, (2) run through the pretraining alley from start- to goalbox, and (3) push through the doors. Stage 1 spanned 4 days during which each $S$ received $10 \mathrm{~min}$ of free drinking from the water cup per day. On Days 3 and 4 , the access door to this cup was in place. During Stage 2, all Ss were given a total of 14 runs from start- to goalbox in the pretraining alley. These trials were spread over a period of 4 days, with each $S$ receiving no more than five trials on a single day. As these trials were administered, the doors were progressively lowered from a completely raised position to a position that allowed a $3.81-\mathrm{cm}$ (1 $1 \frac{1}{2}$-in.) clearance between the door and alley floor. Stage 3 consisted of 45 trials over a period of 5 days with the doors completely down, i.e., with $0.64 \mathrm{~cm}(1 / 4$ in.) clearance.

Testing consisted of 45 trials in the test apparatus. On the first day, each rat received 1 free trial with no doors. blocked, followed by 2 test trials. The free trial was administered in order to assess position preferences. On Test Day 2 , all rats received three test runs.

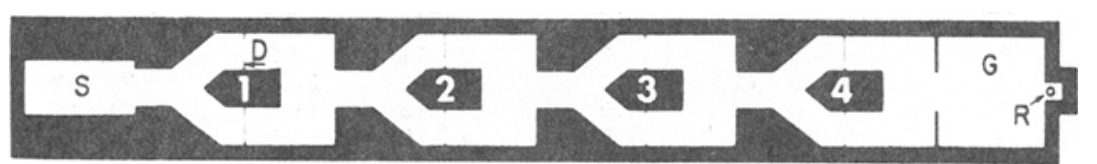




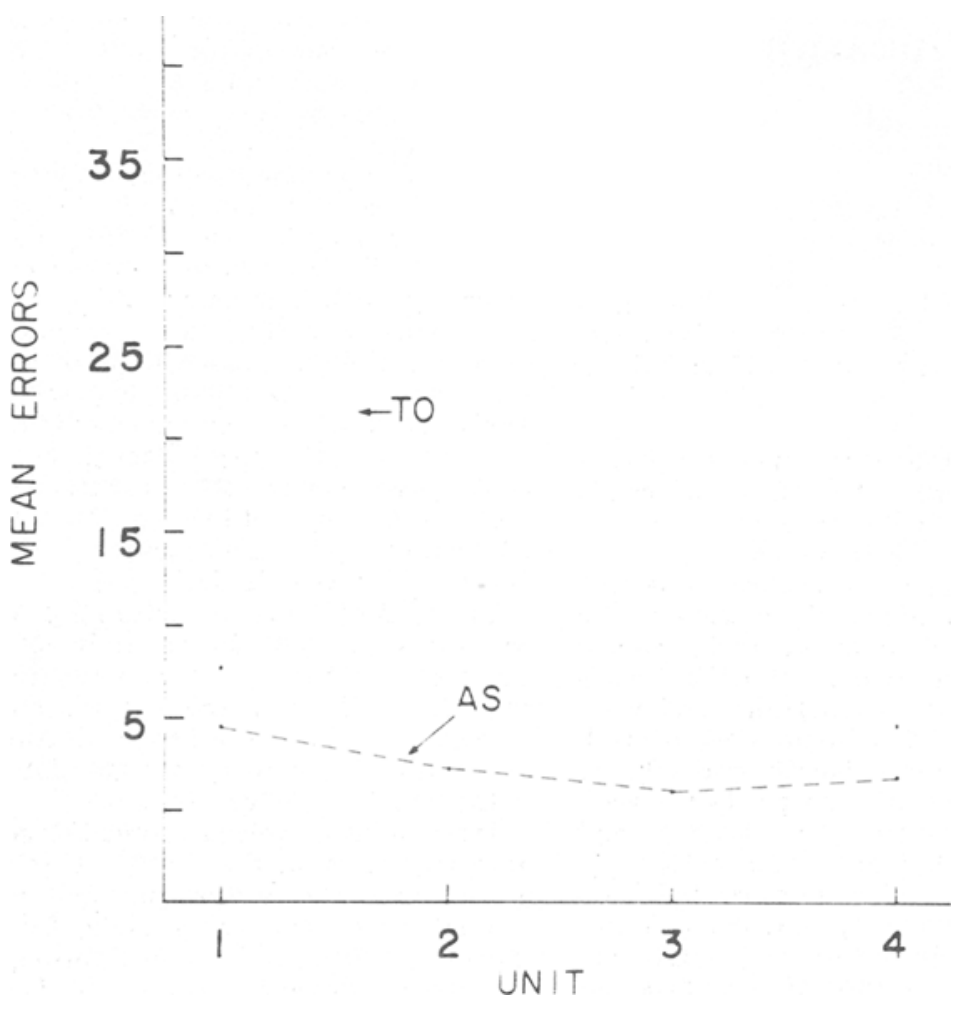

Fig. 2. Mean errors at each choice point.

For the 8 remaining test days, each rat received 5 consecutive trials per day.

$$
\text { DESIGN }
$$
same), all four correct choices were to the left and, for the other half, all four correct choices were to the right. For half of Group TO (terminal opposite), the first three correct choices proceeding from the startbox were to the left and the last choice before the goalbox was to the right. For the other half of the Ss in Group TO, the first three correct choices were to the right and the last correct choice was to the left.

\section{SUBJECTS}

The Ss were 225- to 249-g male albino rats purchased from the
For half of the Ss in Group AS (all

Berkeley Pacific Laboratories. One S was lost during pretraining, and 6 Ss ( 3 from Group AS and 3 from Group TO) were lost during testing because of failure to complete a trial or because of errors made by $E$. Additional Ss were discarded randomly so that there would be $14 \mathrm{Ss}$ in Group AS and 14 Ss in Group TO and so that, within each group, the number of Ss that had left choices correct would be the same as the number that had right choices correct for each choice point.

\section{RESULTS}

The means of the total errors made at each choice point by Groups AS and TO are shown in Fig. 2. In general, the results of Sprow (1947) and

Table 1

Errors in the Test Apparatus

\begin{tabular}{|c|c|c|c|c|c|c|c|}
\hline \multirow{2}{*}{$\begin{array}{l}\text { Choice } \\
\text { Point }\end{array}$} & \multicolumn{3}{|c|}{ Group AS } & \multicolumn{3}{|c|}{ Group TO } & \multirow[b]{2}{*}{ Chi Square } \\
\hline & & Inge & Median & & ange & Median & \\
\hline 1 & 1 & 15 & 2.5 & 1 & 17 & 6.0 & $5.17^{*}$ \\
\hline 2 & 0 & 11 & 1.0 & 17 & 43 & 33.0 & $24.14 t$ \\
\hline $\mathbf{3}$ & 0 & 3 & 1.0 & 29 & 43 & 41.0 & $24.14 \dagger$ \\
\hline 4 & $\mathbf{0}$ & 4 & 1.5 & 1 & 18 & 3.0 & $5.17^{*}$ \\
\hline Total & 3 & 31 & 6.5 & 67 & 101 & 82.5 & $24.14 \dagger$ \\
\hline
\end{tabular}

${ }^{*} p<.001,+p<.05$
Gladstone (1948) for conditions similar to those of Group AS and the results of Carpenter (1952) for conditions similar to those of Group TO were replicated. Somewhat fewer errors were obtained for Group AS and somewhat more errors were obtained for Group TO than would have been expected from the earlier experiments. For Group AS, a slight and statistically insignificant increase in errors was found at Unit 4 as compared to the number of errors at Unit 3, which replicates both in size and direction an effect found in the earlier experiments.

The analysis of the differences between Groups AS and TO was performed by median tests (Siegel, 1956 , pp. 111-116) as shown in Table 1. Group TO made significantly more errors than Group AS at each choice point, and there was no overlap in scores between the two groups either for errors made at Units 2 and 3 or for total errors. Analysis of the differences between errors made at different choice points was performed separately for Group AS and for Group TO by the McNemar Test (Siegel, 1956, pp. 63-67). For Group TO the differences were all significant $(\mathrm{p}<.01$, or smaller $)$ except for the difference between Units 1 and 4, For Group AS, significantly more errors were made at Unit 1 than were made at each of the remaining three choice points ( $\mathrm{p}<.05$, or smaller), but the numbers of errors made at Units 2,3 , and 4 were not significantly different from each other.

We conclude that the early findings with rats in the linear maze can be replicated readily and that anticipatory errors under the conditions presented to Group TO can serve as a sensitive measure of the goal-gradient phenomenon.

\section{REFERENCES}

CARPENTER, J. A. Anticipatory behavior in the rat following frontal lesions. Journal of Comparative \& Physiological Psychology, 1952, 45, 41 3-418.

GLADSTONE, A. I. Reactively homogeneous compound trial-and-error learning with distributed trials and serial reinforcement. Journal of Experimental Psychology, 1948, 38, 289-297.

KIMBLE, G. A. Hilgard and Marquis' Conditioning and learning. New York: Appleton-Century-Crofts, 1961.

SIEGEL, S. Nonparametric statistics for the behalioral sciences. New York: McGraw-Hill, 1956.

SPROW, A. J. Reactively homogeneous compound trial-and-error learning with distributed trials and terminal reinforcement. Joumal of Experimental Psychology, 1947, 37, 197-213. 